http://jmscr.igmpublication.org/home/ ISSN (e)-2347-176x ISSN (p) 2455-0450 crossref DOI: https://dx.doi.org/10.18535/jmscr/v8i3.15

\title{
Comparison of Efficacy of Dexmedetomidine versus Lignocaine in Attenuation of hemodynamic response to laryngoscopy and intubation
}

\author{
Authors \\ Dr Tanushree Vijay*, Dr Kavyashree H S
}

Sri Siddhartha Medical College Hospital \& Research Centre, Agalakote, Tumakuru, Karnataka-572107 *Corresponding Author

Dr Tanushree V

Junior Resident, Department of General Medicine, Sri Siddhartha Medical College Hospital \& Research Centre, Tumakuru, Karnataka, India

\begin{abstract}
Background: The present study is to compare the efficacy of dexmedetomidine versus Lignocaine to attenuate hemodynamic response occurring due to laryngoscopy and endotracheal intubation in elective general surgery.

Methods: A total of 60 patients aged 18-60 years, American Society of Anesthesiologists physical status I or II, either sex, scheduled for elective surgical procedures were included in this study. Patients were randomly using a computer generated random number table to two equal groups of 30 each, comprising of group dexmedetomidine (group D) $1 \mu \mathrm{g} / \mathrm{kg}$ diluted with $0.9 \%$ saline to $10 \mathrm{ml} \mathrm{I}$.V. over 10min and group (L) $1.5 \mathrm{mg} / \mathrm{Kg}$ of Lignocaine diluted with $0.9 \%$ saline $10 \mathrm{ml} \mathrm{I}$.V. given just before induction. Heart rate, systolic blood pressure, diastolic blood pressure, and mean arterial pressure were recorded at baseline, after 3 min of infusion, after induction and at 1, 3, 5 and 10 min after endotracheal intubation.

Results: In group D, there was no statistically significant increase in HR and blood pressure after intubation at any time intervals, where as in group L, there was a statistically significant increase in blood pressure and heart rate after intubation at 1, 3, 5 and 10 min.

Conclusions: Dexmedetomidine $1 \mu \mathrm{g} / \mathrm{kg}$ is more effective in attenuating the hemodynamic response to laryngoscopy and intubation than Lignocaine $1.5 \mathrm{mg} / \mathrm{Kg}$ in elective surgical patients.

Keywords: Dexmedetomidine, Lignocaine, hemodynamic response, laryngoscopy.
\end{abstract}

\section{Introduction}

Laryngoscopy and endotracheal intubation evoke marked sympathetic response that causes increase in the heart rate, blood pressure, intraocular and intracranial pressure ${ }^{1}$. These changes are seen maximum immediately after intubation and last for 5 to 10 minutes. The agents that can be used for alleviate this response are topical or intravenous (I.V.) lidocaine, opioids, inhaled anesthetics, vasodilators, calcium channel blockers or adrenergic blockers. $^{2}$

Dexmedetomidine is an imidazole derivative and selective $\alpha 2$ adrenergic receptor agonist which produces hyperpolarization of noradrenergic neurons and suppression of neuronal firing in the locus ceruleus which leads to decreased systemic noradrenaline release resulting in attenuation of sympathoadrenal responses and hemodynamic 
stability during laryngoscopy and tracheal intubation. $^{3}$

Lignocaine is an aminoethylamide and prototype of amide local anesthetic group.It is the most widely used local anesthetic drug having membrane stabilizing action, so it is commonly used as an anti-arrhythmic drug in patients with ventricular ectopics. In 1961, Bromage showed that its intravenous (IV) use blunted pressure response to intubation. ${ }^{4}$

This study was conducted to compare the efficacy of dexmedetomidine versus Lignocaine in attenuating hemodynamic response to laryngoscopy and intubation

\section{Methods}

After obtaining institutional ethical committee clearance, 60 ASA I and II patients between age 18 - 60 years were selected posted for elective surgeries under general anesthesia with controlled ventilation. Patients with anticipated difficult airway, laryngoscopy time more than 20 seconds, on preoperative $\beta$ blockers, with history of asthma, hypertension diabetes, hepatic failure and renal failure, pregnant and lactating women were excluded from the study. Patients were allocated into two groups namely- Group D and Group P (Placebo) using a computer generated random number table.

In the operative room, an $18 \mathrm{G}$ IV cannula was secured and monitors attached. Inj. Glycopyrrolate $0.005 \mathrm{mg} / \mathrm{Kg}$ was given. Group D (dexmedetomidine group) patients were given I.V. dexmedetomidine $1 \mu \mathrm{g}$ per $\mathrm{kg}$ in $10 \mathrm{ml}$ normal saline infused over 10 mins before intubation and Group L were given $2 \%$ Lignocaine $1.5 \mathrm{mg} / \mathrm{Kg}$ IV in $10 \mathrm{ml}$ normal saline bolus over 10 minutes just before induction. After 5 mins of stabilizing period SBP, DBP, MAP, Heart rate, SpO2 were recorded. All patients were pre-oxygenated with 100\% O2 for $3 \mathrm{~min}$. Anesthesia was induced by inj. thiopentone $5 \mathrm{mg} / \mathrm{kg} \mathrm{I.V}$. in graded dose till loss of eye lash reflex, and after confirming ventilation, inj. Succinyl choline $1.5 \mathrm{mg} / \mathrm{kg}$ was given to facilitate laryngoscopy and intubation.
Patients were intubated with appropriate size endotracheal tube within $20 \mathrm{sec}$, after conforming air entry bilateral equal, tube was fixed and secured. Anesthesia was maintained with $\mathrm{O} 240 \%$ and $\mathrm{N} 2 \mathrm{O} 60 \%$ and intermittent boluses of inj. vecuronium as per requirement .Heart rate, SBP, DBP, MAP, SpO2 were measured at 1, 3, 5 and 10 minutes after intubation.. Bradycardia was treated with inj. atropine $0.6 \mathrm{mg}$ I.V. Any hypotension (SBP (SBP <20\%baseline) was managed initially with a fluid bolus. If unresponsive inj. ephedrine $0.5-0.6 \mathrm{mg} / \mathrm{kg} \mathrm{I.V}$. in graded doses was given. At the end of surgery, when patients regained respiratory attempts, residual neuromuscular blockade was reversed with inj. neostigmine and inj. glycopyrrolate. Recovery was assessed and extubation was carried out. After complete clinical recovery patients were shifted to post anesthesia care unit

\section{Statistical Analysis}

Mean and standard deviation for all values were calculated and compared within the group, with the base line values as well as inter group comparison were done. Paired and unpaired ttests and chi square test were used for statistical analysis. P-value $<0.05$ was considered statistically significant. $\mathrm{P}$ value

\section{Results}

Demographic Data: There was no significant difference in demographic characteristics such as age, weight and sex and both the groups were comparable

Comparison of heart rate (beats/min) between Lignocaine and dexmedetomidine: Mean heart rate at baseline was 79.53 beats/min in group L which was comparable to 80.26 beats/min in group $\mathrm{D}$ and difference was not statistically significant. The heart rate at $1 \mathrm{~min}, 3 \mathrm{~min}, 5 \mathrm{~min}$ and $10 \mathrm{~min}$ after intubation was significantly lesser in the dexmedetomidine group (Table 1) Comparison of SBP (mmHg) between esmolol and dexmedetomidine: The mean SBP at baseline was $120.13 \mathrm{mmHg}$ in group $\mathrm{L}$ which was 
comparable with $119.40 \mathrm{mmHg}$ in group D and the difference was not statistically significant. One minute after intubation mean SBP was $128 \mathrm{mmHg}$ in group D which was significantly less as compared mean SBP of $155.80 \mathrm{mmHg}$ in group L. This difference was statistically significant observed at $1 \mathrm{~min}$. Similar differences were noted at $3 \mathrm{~min}, 5 \mathrm{~min}$ and $10 \mathrm{~min}$ after intubation. (Table 2)

Comparison of DBP (mm $\mathrm{Hg}$ ) between Lignocaine and dexmedetomidine: The mean DBP at baseline was $79.13 \mathrm{mmHg}$ in group L which was comparable with $79.53 \mathrm{mmHg}$ in group D and the difference was not statistically significant. Same trend was observed at 5 min of infusion and at induction. At 1 min after intubation mean DBP was $82.06 \mathrm{mmHg}$ in group $\mathrm{D}$ which was significantly less as compared to mean DBP 89.33
$\mathrm{mmHg}$ in group L. This difference in mean DBP was statistically significant at $1 \mathrm{~min}$ and $3 \mathrm{~min}$. after intubation. However, mean DBP at $5 \mathrm{~min}$ and $10 \mathrm{~min}$ after intubation was comparable between group L and group D and the difference was statistically insignificant (Table 3)

Comparison of MAP (mmHg) between Lignocaine and dexmedetomidine: The mean MAP at baseline was $92.80 \mathrm{mmHg}$ in group $\mathrm{L}$ which was comparable with $92.53 \mathrm{mmHg}$ for group D and the difference was not statistically significant. Same trend was observed at $5 \mathrm{~min}$ of infusion and at induction. At $1 \mathrm{~min}$ after intubation mean MAP was $92.27 \mathrm{mmHg}$ in group D which was significantly less as compared to mean MAP $111.49 \mathrm{mmHg}$ in group L. The difference was statistically significant at $1 \mathrm{~min}, 3$ min, 5 min and 10 min after intubation (Table 4)

Table 1: Comparison of heart rate (beats/min) between Lignocaine and dexmedetomidine

\begin{tabular}{|l|l|l|l|}
\hline PARAMETER & LIGNOCAINE & DEXMEDETOMIDINE & P Value \\
\hline HR at Baseline & $79.53 \pm 3.39$ & $80.26 \pm 2.44$ & $0.38 .(\mathrm{NS})$ \\
\hline 5 minutes After Infusion & $79.66 \pm 2.97$ & $79.13 \pm 2.66$ & $0.53 .(\mathrm{NS})$ \\
\hline HR at induction & $77.60 \pm 2.64$ & $76.80 \pm 2.75$ & $0.22 .(\mathrm{NS})$ \\
\hline HR at 1 min after intubation & $86.93 \pm 4.44$ & $81.33 \pm 3.33$ & $<0.0001 .{ }^{*}$ \\
\hline HR at 3min after intubation & $85.86 \pm 3.99$ & $79.33 \pm 3.37$ & $<0.0001 .{ }^{*}$ \\
\hline HR at 5min after intubation & $83.66 \pm 4.003$ & $76.13 \pm 3.14$ & $<0.0001 .{ }^{*}$ \\
\hline HR at 10 min after intubation & $80.53 \pm 3.52$ & $74.73 \pm 2.94$ & $<0.0001 . *$ \\
\hline
\end{tabular}

Table 2: Comparison of SBP ( $\mathrm{mmHg}$ ) between Lignocaine and dexmedetomidine

\begin{tabular}{|l|c|c|c|}
\hline PARAMETER & LIGNOCAINE & DEXMEDETOMIDINE & P Value \\
\hline SBP at Baseline & $120.13 \pm 4.03$ & $119.40 \pm 4.52$ & $0.51 .(\mathrm{NS})$ \\
\hline SBP5 minutes After Infusion & $120.27 \pm 3.92$ & $119.80 \pm 4.58$ & $0.67 .(\mathrm{NS}$ \\
\hline SBP at induction & $116.20 \pm 3.29$ & $116.07 \pm 3.25$ & $0.73 .(\mathrm{NS})$ \\
\hline SBP at 1min after intubation & $155.80 \pm 9.53$ & $128 \pm 7.33$ & $<0.0001 .{ }^{*}$ \\
\hline SBP at 3min after intubation & $146.80 \pm 9.09$ & $124.20 \pm 6.33$ & $<0.0001 .{ }^{*}$ \\
\hline SBP at 5min after intubation & $133.80 \pm 7.88$ & $119 \pm 4.48$ & $<0.0001 .{ }^{*}$ \\
\hline SBP at 10min after intubation & $120.27 \pm 5.29$ & $114.73 \pm 3.61$ & $<0.0001 .{ }^{*}$ \\
\hline
\end{tabular}

Table 3: Comparison of DBP $(\mathrm{mmHg})$ between Lignocaine and dexmedetomidine

\begin{tabular}{|l|c|c|c|}
\hline PARAMETER & LIGNOCAINE & DEXMEDETOMIDINE & P Value \\
\hline DBP at Baseline & $79.13 \pm 5.88$ & $79.53 \pm 4.59$ & $0.5517 .(\mathrm{NS})$ \\
\hline DBP 5 minutes After Infusion & $78.66 \pm 5.39$ & $79.33 \pm 5.66$ & $0.64 .(\mathrm{NS})$ \\
\hline DBP at induction & $73.60 \pm 5.13$ & $76.53 \pm 7.51$ & $0.17 .(\mathrm{NS})$ \\
\hline DBP at 1min after intubation & $89.33 \pm 6.65$ & $82.06 \pm 8.008$ & $<0.0006 .{ }^{*}$ \\
\hline DBP at 3min after intubation & $80.26 \pm 7.67$ & $74.86 \pm 8.26$ & $<0.0081 .{ }^{*}$ \\
\hline DBP at 5min after intubation & $74.66 \pm 5.68$ & $71.86 \pm 7.12$ & $0.59 .(\mathrm{NS})$ \\
\hline DBP at 10min after intubation & $71.60 \pm 5.71$ & $69.26 \pm 6.203$ & $0.12 .(\mathrm{NS})$ \\
\hline
\end{tabular}


Table 4: Comparison of MAP $(\mathrm{mmHg})$ between Lignocaine and dexmedetomidine

\begin{tabular}{|l|c|c|c|}
\hline PARAMETER & LIGNOCAINE & DEXMEDETOMIDINE & P Value \\
\hline MAP at Baseline & $92.80 \pm 5.108$ & $92.53 \pm 4.62$ & $0.79 .(\mathrm{NS})$ \\
\hline MAP 5 minutes After Infusion & $92.53 \pm 4.62$ & $92.82 \pm 4.60$ & $0.80 .(\mathrm{NS})$ \\
\hline MAP at induction & $87.80 \pm 4.19$ & $89.71 \pm 5.25$ & $0.12 .(\mathrm{NS})$ \\
\hline MAP at 1min after intubation & $111.49 \pm 7.26$ & $97.27 \pm 5.41$ & $<0.0001 .{ }^{*}$ \\
\hline MAP at 3min after intubation & $102.44 \pm 7.76$ & $91.31 \pm 5.38$ & $<0.0001 .{ }^{*}$ \\
\hline MAP at 5min after intubation & $94.37 \pm 5.99$ & $87.57 \pm 4.88$ & $<0.0001 .{ }^{*}$ \\
\hline MAP at 10min after intubation & $87.82 \pm 5.39$ & $84.42 \pm 4.38$ & $0.0127 .{ }^{*}$ \\
\hline
\end{tabular}

\section{Discussion}

The pressor response to laryngoscopy and endotracheal intubation in the form of tachycardia, hypertension and arrhythmias, though transient, may be potentially dangerous. This response is due to reflex sympathetic discharge caused by epipharyngeal and laryngopharyngeal stimulation. Transient hypertension and tachycardia are probably of no consequence in healthy individuals but either or both may be hazardous to those with hypertension, myocardial insufficiency and cerebrovascular disease. These changes are the maximal at 1 minute after intubation and last for 5-10 minutes. Prophylaxis include topical lignocaine sprays, deeper planes of anaesthesia by inhalational agents; narcotics, calcium channel blockers, vasodilators such as sodium nitroprusside; nitroglycerin etc, but they have got side effects such as sedation, respiratory depression, hypotension and bradycardia. ${ }^{4}$

In the present study the haemodynamic response to laryngoscopy and intubation were studied for a period of $10 \mathrm{~min}$ as this is the average period for which haemodynamic changes are believed to last.It was found that with this dose dexmedetomidine had better control over HR, SBP, DBP and MAP even after laryngoscopy and intubation. There was significant increase in heart rate and blood pressure from baseline after laryngoscopy and intubation in both groups, maximum rise in heart rate and blood pressure was noted at one minute after intubation but the rise in heart rate and blood pressure in dexmedetomidine group was significantly lower, less pronounced and shorter lasting as compared to Lignocaine group. On comparison between the two groups, the heart rate and blood pressure was better controlled with dexmedetomidine than esmolol after laryngoscopy and intubation over period of 10 minutes which was consistent with a study conducted by Gupta $\mathrm{H} \mathrm{B}^{4}$

Similar result about dexmedetomidine to control HR and blood pressure after laryngoscopy observed in Lee JH et al, Bajwa SS et al and Efe EM et al study ${ }^{5}$

Keniya VM et al study observed that bradycardia occurred in two patients in dexmedetomidine group intraoperatively. ${ }^{6}$ Decrease in HR was observed in our study in permissible limit but none of our patients required treatment with atropine

In our study, 1 min after laryngoscopy and subsequent intubation SBP and DBP was $12.8 \%$ and $9.7 \%$ below baseline values. Similarly, HR remained $8.13 \%$ below baseline in dexmedetomidine group

\section{Conclusion}

Efficacy of dexmedetomidine in attenuation of the pressor response compared to intravenous lignocaine $(1.5 \mathrm{mg} / \mathrm{kg})$ is significantly higher

\section{References}

1. Miller R, editor. Airway management. In: Miller's Anesthesia. VIIIth ed. Philadelphia: Churchill Livingstone; 2019. p. 1647-8.

2. Shribman AJ, Smith G, Achola KJ. Cardiovascular and catecholamine responses to laryngoscopy with and without tracheal intubation. Br J Anaesth, 1987;59:295-9 
3. Grewal A. Dexmedetomidine: new avenues. J Anaesthesiol Clin Pharmacol. 2011;27:297-302.

4. Gupta HB et al. Int J Basic Clin Pharmacol. 2016 Oct;5(5):1803-1808

5. Bajwa SS, Kaur J, Singh A, Parmar SS, Singh G, Kulshrestha A, et al. Attenuation of pressor response and dose sparing of opioids and anaesthetics with preoperative dexmedetomidine. Indian $\mathrm{J}$ Anaesth. 2012;56:123-8.

6. Keniya VM, Ladi S, Naphade R. Dexmedetomidine attenuates sympathoadrenal response to tracheal intubation and reduces perioperative anaesthetic requirement. Indian J Anaesth. 2011;55:352-7. 